\title{
The relationship between health literacy level and self-care ability in the
}

\section{elderly}

\author{
TamizKar $\mathrm{P}^{1}$, Mohammadi $\mathrm{M}^{2}$, Fathnezha-kazemi A ${ }^{3}$ **Marami $\mathrm{S}^{4}$
}

1- Student Research Committee, Islamic Azad University, Tabriz Branch, Tabriz, Iran.

2- Student Research Committee, Islamic Azad University, Tabriz Branch, Tabriz, Iran.

3- Ph. D of Reproductive Health, Department of Midwifery, Tabriz Branch, Islamic Azad University, Tabriz, Iran. 4-Student Research Committee, Islamic Azad University, Tabriz Branch, Tabriz, Iran (Corresponding author) Email: somayehmaramid@gmail.com

\section{Abstract}

Introduction: Elderly people with low levels of health literacy are one of at-risk groups because they have difficulty understanding and reading health information that may affect their health care. The aim of this study was to determine the relationship between health literacy status and self-care ability in the elderly in Tabriz.

Method: This cross-sectional descriptive-analytical study was conducted in 2019 with the participation of 165 elderly people in the Tabriz Retirement Center. Sampling was done randomly and considering the inclusion criteria. The tools were used consisted of three sections: demographic characteristics, health literacy and self-care questionnaire. Data were analyzed by SPSS v.21 and the level of significance considered was $(\mathrm{P}<0.05)$.

Results: The mean (standard deviation) age and body mass index were 66.47 (5.44) and 26.75 (1.90) and $52.7 \%$ of the male participants, respectively. The mean (standard deviation) score of health literacy and self-care ability were 79.58 (11.80) and 68.95 (6.37), respectively. Most of the elderly $143(86.7 \%)$ had adequate and higher level of health literacy. Also $83(50.3 \%)$ had low selfcare ability. There was a positive and significant relationship $(\mathrm{P}<0.05)$ between health literacy and self-care ability, although this relationship was weak $(r=0.20)$.

Conclusion: Although the level of health literacy was moderately high, however many people had insufficient self-care ability. Indicates the need to pay attention to the relevant factors in order to plan and take measures to improve the self-care capacity of the relevant authorities.

Keywords: literacy, Health, Self-care, Aged. 


\section{ارتباط سطح سواد سلامت با توان خودمر اقبتى در سالمندان}

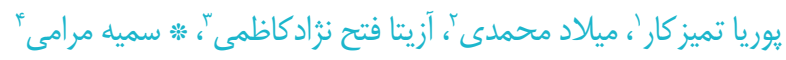

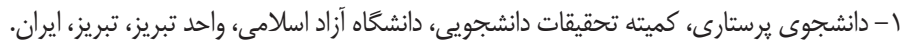

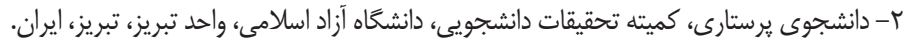

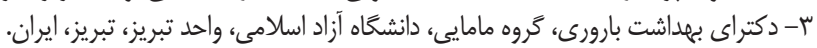

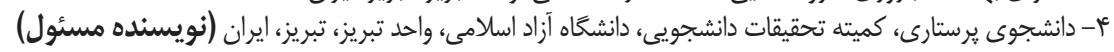
يست الكترونيكى: somayehmaramid@gmail.com

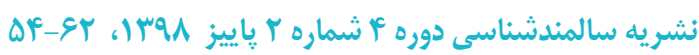

\section{جوك:}

مقدمه: افراد سالمند با سطح سواد سلامت يايين، يكى از گروه هاى در معرض خطر هستند زيرا داراى مشكلاتى در فهم و ادراك و

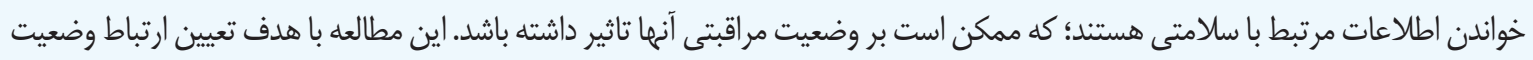
سواد سلامت و توان خودمراقبتى در سالمندان شهر تبريز انجام شد.

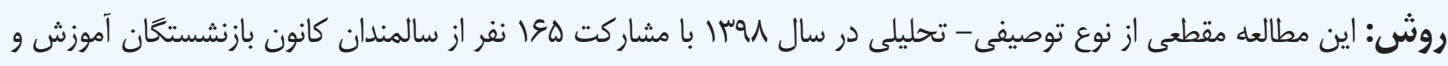
يرورش در شهر تبريز انجام گرفت. نمونه گيرى به صورت تصادفى و با در نظر گرفتن معيارهاى ورود به مطالعه انجام شد. ابزار مورد استفاده

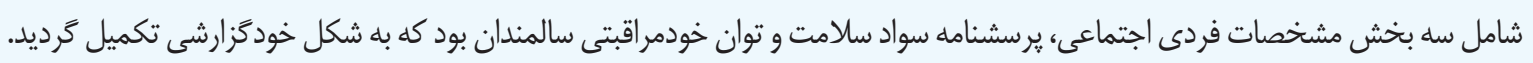

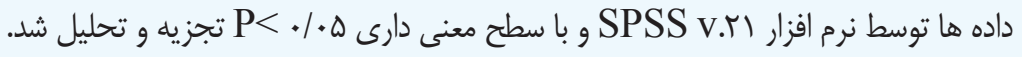

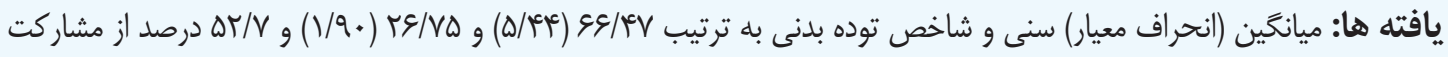
كنند

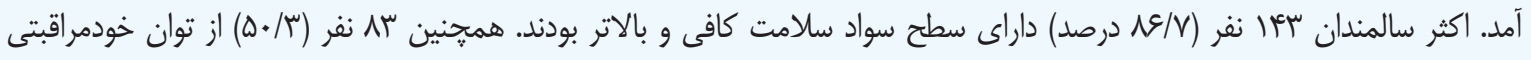
קإيينى برخوردار بودند. ارتباط مثبت و معنى دارى (ه+/ (P<) بين سواد سلامت و توان خودمراقبتى بدست آمد هر جند اين ارتباط ضعيف

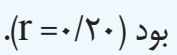

نتيجه كَيرى: با وجود آن كه سطح سواد سلامت در حد متوسط به بالا بود؛ با اين وجود بسيارى از افراد از توان خودمراقبتى ناكافى

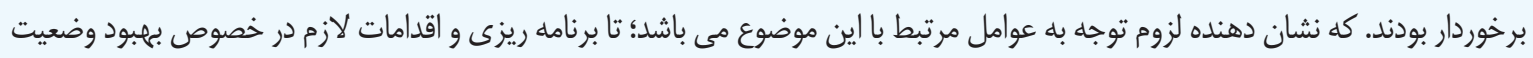

$$
\text { توان خودمراقبتى از سوى مسئولين مربوطه صورت گيرد. }
$$

نفر برسد (أl). يديده سالمندى نتيجه سير طبيعى زمان است كه منجر مقلهمه به تغييرات فيزيولوزيكى، روانى و اجتماعى مى شود (هـ). سالمندان به علت تغييرات فيزيولوزيك كه با بالارفتن سن رخ مى دهد؛ بيش از سنين ديخر به بيمارى هاى گوناگون مبتلا مى شوند (V، (V). با افزايش قابل توجه سالمندان، بهبود كيفيت زندكى و حفظ سلامتى فيزيكى افراد سالمند اهميت فراوانى مى يابد (^ِ). مطالعات اخير روى سالمندان نشان داده اند، كه سواد سلامت كم با خودارزيابى از وضعيت سلامت پايين و همٍنين افزايش مرگ ومير سالمندان مرتبط است (ه، (). سواد سلامت ميزان ظرفيت فرد افزايش خشمخير جمعيت سالمندى در سراسر دنيا، بديده اى

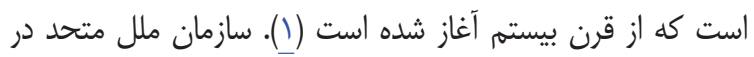
سال צ..r تعداد كل افراد سالمند جهان را \&AV ميليون و سجو هزار نفر ذكر كرده است كه اين تعداد در سال •ه•r به رقم يك ميليارد

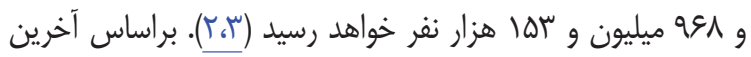

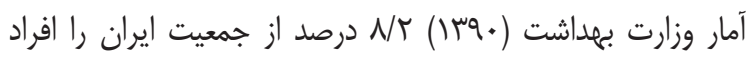
بالاى •و سال تشكيل مى دهند (بَ). ييش بينى مى شود تا سال

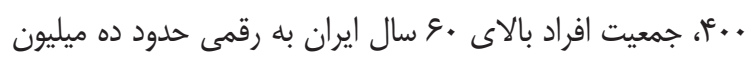


كلى •و درصد از هزينه مراقبت هاى يزشكى توسط اين كروه سنى مصرف مى شود (19،19). مطالعات ديكر نشان مى دهند كه حدود

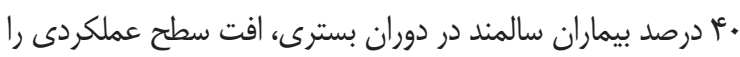

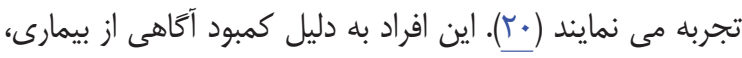
درمان و همجنين نحوه مراقبت از خود، ناتوانى هاى جسمى و مشكلات روانى اجتماعى بيشترى را تجربه نمايند (19). با وجود اهميت بسيار زياد امر سواد سلامت و خودمراقبتى سالمندان ساكن جامعه، متأسفانه به اندازه كافى به اين موضوع توجه كافى نشده است و على رغم رشد جمعيت سالمندان و تغييرات هرم جمعيتى كشور، هنوز بر نيازهاى سالمندان به عنوان يك گروه آسيب يذير جامعه تمركز نشده است. اين يثوهش با هدف تعيين وضعيت و ارتباط سطح سواد سلامت و توان خود مراقبتى در سالمندان كانون بازنشستخان آموزش و يرورش شهر تبريز در سال يوسا طراحى شد.

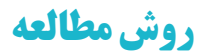

اين مطالعه مقطعى از نوع توصيفى - تحليلى از ابتداى تير تا اواخر مرداد يهجا در كانون بازنشستكان آموزش و يرورش در شهر تبريز انجام گرفت. جامعه آمارى شامل تمام سالمند كانون

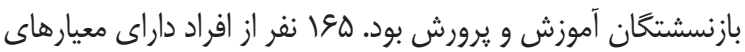
ورود به مطالعه وارد مطالعه شدند. پِ از كسب مجوز براى نمونه كَيرى، تمام افراد واجد شرايط ليست شده و به هر نفر شماره اي تعلق كَرفت. سيس افراد به صورت تصادفى ساده، با استفاده از رايانه و نرم افزار Randomizer انتخاب شدند. سيّ با تماس تلفنى از افراد خواسته شد در صورت مشاركت در جلسات كانون كه هر هفته يك بار صورت مى گيرد؛ جهت مشاركت در مطالعه اعلام آمادگى كنند.

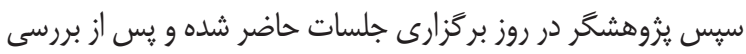
دوباره از نظر معيارهاى ورود و پِّ از كسب رضايت نامه كتبى ترولى از مشاركت كنندكان و توضيح در مورد مطالعه از آنها مى خواست

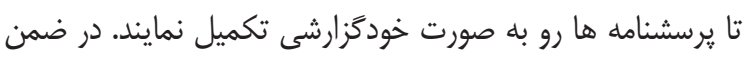

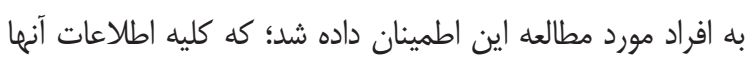
محرمانه خواهد ماند. در صورت عدم دسترسى به افراد منتخب و يا عدم تمايلى به شركت در مطالعه، نفر بعدى كه به صورت تصادفى در فهرست قرار مى گرفت و جايكزين مى شد. نمونه گيرى تا رسيدن
براى كسب، تفسير و درك اطلاعات اوليه و خدمات بهداشتى است كه براى تصميم گيرى مناسب لازم است و شامل مجموعه اي از مهارت هاى خواندن، شنيدن، تجزيه و تحليل، تصميم كَيرى و

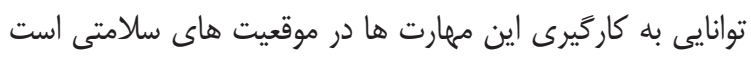
كه لزوما به سالماى تحصيل يا توانايى خواندن عمومى بر نمى كرددد

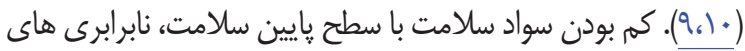
كَسترده تر و هزينه هاى بالاتر نظام سلامت همراه است ((). از طرفى متاسفانه سطح پايين سواد سلامت در گروه سالمندان شايع تر است (ז/،(1)، در نتيجه اين افراد به عنوان گروه هاى در معرض خطر اثرات ناخوشايند سطح بايين سواد سلامت به شمار مى روند

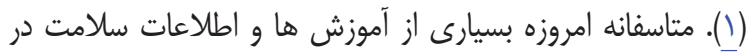
سيستم بهداشتى به صورت نوشتارى است كه متن آنها قابل فهم براى بسيارى از افراد به خصوص سالمندان نيست (با)، بنابراين

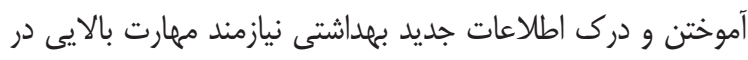
خواندن، محاسبات و مهارت تصميم گيرى است و بسيارى از يزشكان بر اين باورند كه بيماران توانايى خواندن و نيز درك تمام دستورالعمل هاى سلامت را دارند ( (). اين در حالى است كه مطالعات ثابت كردند، كه اغلب سالمندان در اين سه زمينه مهارت كافى ندارند و ضعيف

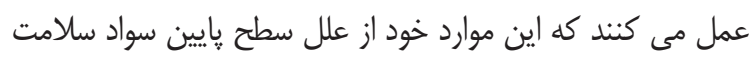

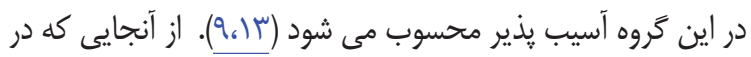

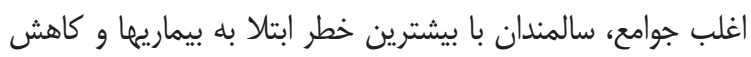

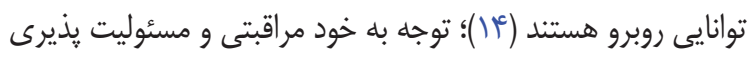
سالمندان در قبال بيمارى هاى مختلف يكى از راهكارهاى حمايتى به شمار مى آيد كه نيازمند سطح بالايى از سواد سلامت است (ه) . اصل مهم در مراقبت از خود، مشار كت و قبول مسئوليت از طرف خود بيمار، داشتن توانايى براى انجام دادن فعاليت هاى مراقبت از خود و توانايى درك و شناخت اين فعاليت هاست (عا). توان خودمراقبتى تحت تاثير عوامل مختلفى همجِون سن، جنس، وضعيت تكاملى،

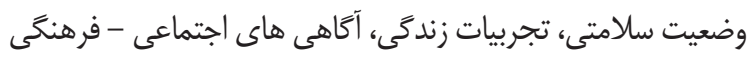

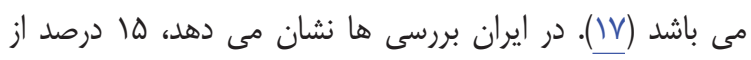

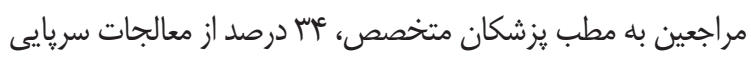
در بيمارستان ها و 19 درصد از تخت هاى مؤسسات و سراهاى نكَّهدارى را افراد بالاى هQ سال به خود اختصاص مى دهندو به طور 
F به عنوان سواد سلامت كافى، عم تا ... به عنوان سواد سلامت عالى در نظر گَرفته مى شوند (آr). منتظرى و همكاران طى يخوهشى به طراحى و روانسنجى اين ابزار يرداختند و آن را داراى روايى مطلوب

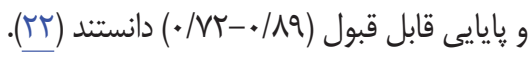
محاسبه حجم نمونه

پس از كنترل اهداف تحقيق جهت تعيين حجم نمونه، بيشترين حجم نمونه محاسبه شد. به طورى كه براساس مطالعه فتحى و همكاران (V) و با در نظر گرفتن ع درصد و با در نظر گرفتن

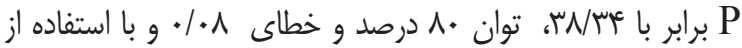
فرمول محاسبه نسبت هايق حجم نمونه اوليه عأ| نفر برآرود شد و

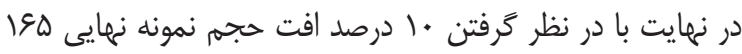
نفر تعيين شد.

$$
n=\frac{Z^{2}{ }_{1-\frac{a}{2}} \cdot p(1-p)}{d^{2}}
$$

$$
\text { آناليز داده ها }
$$

جهت تجزيه و تحليل داده ها براى داده هاى كمى از ميانگين و انحراف معيار و براى داده هاى كيفى از درصد و فراوانى استفاده شد. همجنين يس از كتترل نرمال بودن داده ها از آمار تحليلى براى داده هاى كمى از تى مستقل و ANOVA استفاده شد. جهت بررسى ارتباط بين دو متغير اصلى، همبستخى ييرسون مورد استفاده

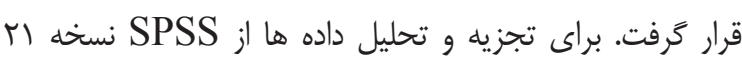
استفاده شد. سطح معنى دارى ه+, ••> معنى دار تلقى شد.

\section{كافته ها}

نمونه گَيرى تا رسيدن به هاء نفر ادامه يافت. تعداد هأ نفر حاضر به مشاركت در مطالعه نشدند. بررسى داده ها نشان داد كه بيشتر مشاركت كنندكان جنسيت مرد داشته و اكثريت آنها (F/F درصد) عس نقر بالاى VD سال بودند. همجنين از نظر تحصيلات بيشتر مشاركت كنندكان داراى تحصيلات بالاتر از دييلم (N/V)

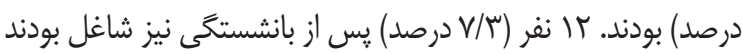

به حجم نمونه محاسبه شده ادامه يافت.

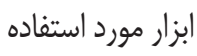

קֶ ليست مشخصات دموكرافيك: شامل سن، جنس، تحصيلات، وضعيت تاهل، قد و وزن و منابع دريافت اطلاعات بهداشتى بود.

يرسشنامه توانايى خود مراقبتى افراد سالمند Self-care Ability Scale (SASE براى ارزيابى توانايى خود مراقبتى افراد سالمند است. ياسخ هر سؤال براساس مقياس ليكرت است كه امتيازات بين ا تا ه تقسيم بندى شده است. پاسخ به سؤالات به صورت كاملا موافقم، موافقم، نظرى ندارم، مخالفم و كاملا مخالفم مى باشد، ؟ آيتم بار منفى دارند؛ كه

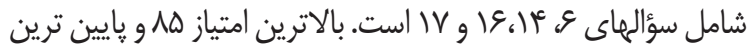
امتياز IV مى باشد. نمره كمتر از وع نشان دهنده توان خودمراقبتى ״ايين و نمره مساوى و بيشتر از و نشان دهنده توان خودمر اقبتى بالا مى باشد. محاسبه ضريب آلفاى كرونباخ مؤيد همسانى درونى بالاى

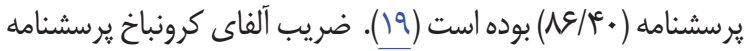
در مطالعه حاضر نيز، پايا بودن آن را مجددا تاييد كرد (•^/•).

\begin{tabular}{|c|c|c|c|}
\hline مينيمهم & ماگزيمم & (انحر اف معيار) & متغير \\
\hline
\end{tabular}
يرسشنامه سطح سواد سلامت: اين يرسشنامه داراى سب گويه اصلى است و توانايى افراد را در ابعاد مختلف سواد سلامت شامل

(دسترسى) ع سؤال (درى و فهم V سؤال، ارزيابى ع سؤال و تصميه گيرى و به كارَيرى اطلاعات سلامت rا سؤال مى سنجد. مقياس نمره دهى اين يرسشنامه بصورت ليكرت ه گزينه اى مى باشد و امتيازات از ا تا ه مى باشد. نحوه امتيازدهى در اين ابزار بدين شكل مى باشد كه ابتدا امتياز خام هر فرد در هر يك از حيطه ها از جمع جبرى امتيازات به دست مى آيد. سِّ براى تبديل اين امتياز به طيف صفر تا . . ا از فرمول تفاضل نمره خام به دست آمده از حداقل نمره خام ممكن تقسيم بر تفاضل حداكثر امتياز ممكن از حداقل امتياز ممكن استفاده مى شود. در نهايت براى محاسبه امتياز كل، امتيازات تمامى ابعاد براساس طيف · تا ..1 جمع شده و بر تعداد ابعاد ه بعد تقسيهم مى گردد كه نمرات · تا • ه به عنوان سواد

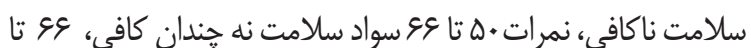


جدول ا: ويثَيهاى فردى و اجتماعى سالمندان شركت كننده در اين مطالعه

\begin{tabular}{|c|c|c|c|c|}
\hline $\begin{array}{l}q \cdot \\
r \cdot / \Delta V \\
1 \Delta \Delta \\
\Delta \varepsilon\end{array}$ & $\begin{array}{l}M \\
r \Delta / 19 \\
\text { IVQ } \\
9 .\end{array}$ & 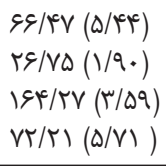 & \multicolumn{2}{|l|}{ 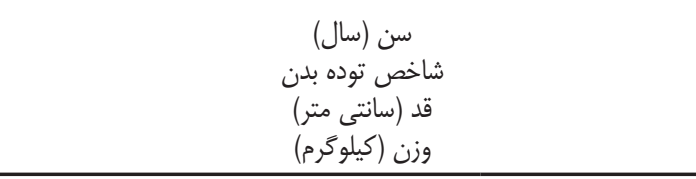 } \\
\hline \multicolumn{3}{|c|}{ (درصد) تعداد } & \multicolumn{2}{|l|}{ متغير } \\
\hline & 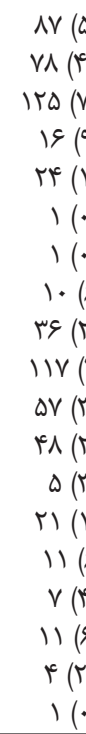 & & 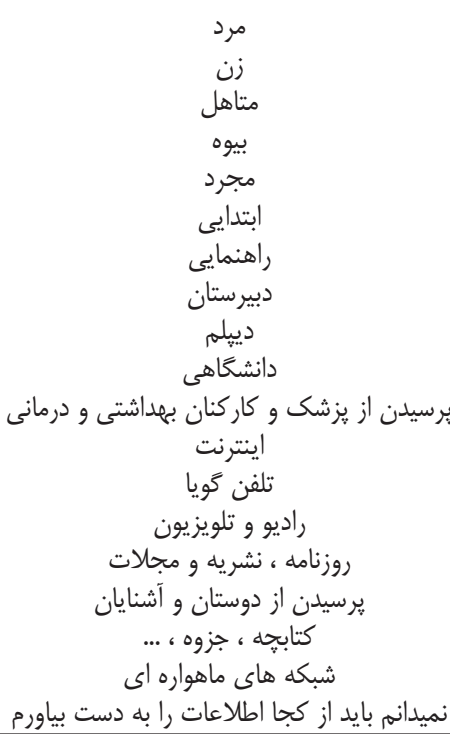 & تجنس \\
\hline
\end{tabular}

درصد افراد سطح سواد سلامت كافى و بالاتر داشتند. بررسى نتايج كسب شده از يرسشنامه توان خودمراقبتى، نشان داد كه ميانخين نمره اين مقياس هـ/NN و سم نفر از افراد شركت كننده توان خودمراقبتى يايينى داشتند (جدول r).
VQ/DA ميانخين نمره كل سواد سلامت در افراد مورد مطالعه

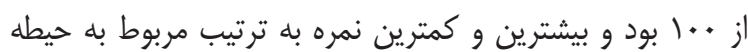
هاى درك و فهم و توانايى ارزشيابى به دست آمد. آنجهه بررسى داده ها نشان داد؛ حاكى از آن بود كه اكثريت افراد از نظر سطح

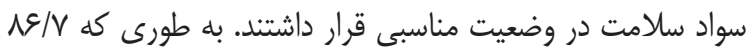

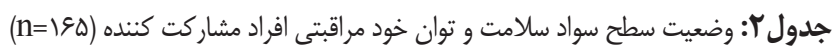

\begin{tabular}{|c|c|c|c|}
\hline كمينه & بيشينه & ميانگين (انحراف معيار) & سواد سلامت \\
\hline 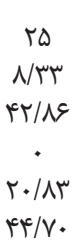 & $\begin{array}{l}1 \ldots \\
1 \ldots \\
1 \ldots \\
1 \ldots \\
1 \ldots\end{array}$ & 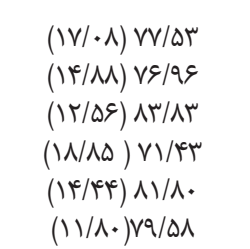 & 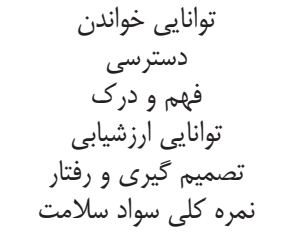 \\
\hline \multicolumn{3}{|c|}{ تعداد (درصد) } & سطوح سطح سواد سلامت \\
\hline \multicolumn{3}{|c|}{ 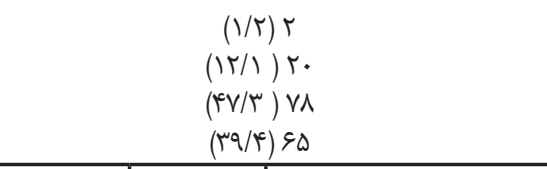 } & نه جنافان كافى \\
\hline كمينه & بيشينه & ميانخين (انحراف معيار ) & توانايى خود مراقبتى \\
\hline tr & $\wedge 1$ & $(\varepsilon / \% V) \& N / 9 \Delta$ & نمره كلى توانايى خود مراقبتى \\
\hline \multicolumn{3}{|c|}{ تعداد (درصد) } & سطوح توان خودمراقبتى \\
\hline \multicolumn{3}{|c|}{$\begin{array}{l}(\Delta \cdot / r) \wedge r \\
(\kappa q / V) \wedge r\end{array}$} & بإيين \\
\hline
\end{tabular}


همجنين ارتباط مثبت و معنى دارى بين حيطه تصميم گيرى وفتار آناليز همبستخى ييرسون، ارتباط مثبت و معنى دارى بين دو

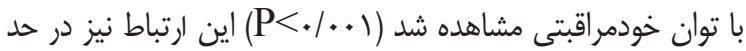

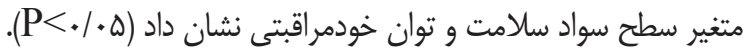

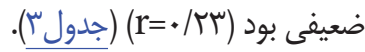
با وجود آن كه اين ارتباط همبستخى ضعيفى (•r=•r/ داشت.

جدول ب: ارتباط بين سطح سواد سلامت و زيرمقياس ها با توان خود مراقبتى

\begin{tabular}{|c|c|c|c|c|c|c|c|c|c|c|c|c|}
\hline \multicolumn{2}{|c|}{ تصميم گيرى و رفتار } & \multicolumn{2}{|c|}{ توانايى ارزشيابى } & \multicolumn{2}{|c|}{ فهم و درك } & \multicolumn{2}{|c|}{ دسترسى } & \multicolumn{2}{|c|}{ توانايى خواندن } & \multicolumn{2}{|c|}{ نمره كل } & \multirow{2}{*}{ متغير } \\
\hline $\mathrm{P}$ & $\mathrm{r}$ & $\mathrm{P}$ & $r$ & $\mathrm{P}$ & $r$ & $\mathrm{P}$ & $r$ & $\mathrm{P}$ & $r$ & $P$ & $r$ & \\
\hline$<\cdot / \cdot \cdot 1$ & rr/. &.$/ 41$ & .1 .94 & $<\cdot / . .1$ & . / &.$/ \mu F^{c}$ & $.1 \cdot V^{c}$ & . & $.1 \cdot 14$ &.$/ \cdot 1$ & $\cdot / r$. & ودمر \\
\hline
\end{tabular}

(جدول)|). با اين وجود با افزايش سطح تحصيلات نمره كل سواد تجزيه و تحليل داده ها حاكى از آن بود كه اختاف معنى سلامت بيشتر بود همجرنين نرمه كل سواد سلامت در افراد متاهل

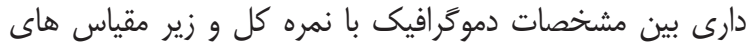
سواد سلامت و با نمره كل توان خود مراقبتى وجود نداشت بيشتر از افراد مجرد بود. جدول f: ارتباط مشخصات دموًر افيك با نمره كل و سطوح مختلف سطح سواد سلامت و خودمراقبتى

\begin{tabular}{|c|c|c|c|c|c|c|c|c|}
\hline توان خود & تصميم كيرى & ارزشيابيى & فهم و درك & دسترسى & توانايى خواندن & احساس يمره كل & \multicolumn{2}{|r|}{ متغير } \\
\hline$\varepsilon q / F V\left(\Delta / V^{c}\right)$ & $\Lambda \mu / . q(\mid \uparrow / r \Lambda)$ & VI/Tg(WN/RT) & $\Lambda \kappa / \cdot r(1) / q \cdot)$ & $\vee \varepsilon / \Lambda \varepsilon(\mid r / \backslash \Lambda)$ & $V \varepsilon / \cdots(I V / I V)$ & $\vee \vee / \wedge \varepsilon(F \backslash / 11)$ & مرد & \\
\hline$G \wedge / \mu \vee(V / \cdot)$ & $\Lambda \cdot / \Psi \varepsilon(\mid \mathcal{\Psi}, \Delta \mathrm{V})$ & $V \backslash / \&$ r $(19, \xi \cdot)$ & 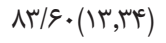 & $V \mathrm{~V} / \cdot \wedge(19,98)$ & $V Q / T f(1 \varepsilon / Q Y)$ & $V q / T \&(I r / T q)$ & زن & جنس* \\
\hline$\cdot / T V$ & $\cdot / r T$ &.$/ 9$ & ./^r &.$/ 9 r$ & $\cdot / \pi T$ & $\cdot / V^{c}$ & $\mathrm{P}$ & \\
\hline$\varepsilon q / \backslash \wedge\left(\Delta / r^{\prime} \varepsilon\right)$ & $\Lambda r / q \cdot(1 r / ৭ q)$ & $V \Gamma / F \Delta(\mid \& / Q \Psi)$ & $\Lambda r / V \backslash(I r / \Lambda r)$ & $V V / \& g(I F / T \Delta)$ & $V / / \Delta \cdot(\mid \& / \Lambda \Delta)$ & $\Lambda \cdot / \cdot 9(1) / \Delta \Delta)$ & متاهل & وضعيت تاهل \\
\hline$\Leftrightarrow \& / \Delta(I) / \Lambda r)$ & $\mathrm{Vq} / \mathrm{r}(\mathrm{q} / \mathrm{M})$ & 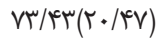 & $\Lambda \mu / \cdot r(৭ / \Lambda \Lambda)$ & $\mathrm{VV} / \wedge \varepsilon(/ Q / \wedge V)$ & $V \varepsilon / \Delta \&(I V / \backslash Q)$ & $V \Lambda / \& q(I r / \Delta \Lambda)$ & بيوه & *** \\
\hline $9 q / 4 r(g / 19)$ & $v q / \cdot r(I r / \Lambda r)$ & SN/AF $(r \Delta / V T)$ & $\Lambda F / q \vee(। r / \backslash \Lambda)$ & $V T / V F(I F / T r)$ & $\checkmark \wedge / \sim \wedge(\mid \Lambda / M \Lambda)$ & $\operatorname{VV} / \Delta r(1 Y / V q)$ & مجرد & \\
\hline . &.$/ 50$ &.$/ I V$ & $\cdot / \wedge \mathrm{V}$ & זr/א &.$/ 94$ & .109 & $\mathrm{P}$ & \\
\hline $9 q / I V(F / q 1)$ & $V V / ৭ \Delta(\mid \mp / ৭ \Delta)$ & $V^{c} / 9 \Delta(q / 4 \cdot)$ & $\Lambda \mu / \cdot r(1 \cdot / \Lambda \Lambda)$ & $V \varepsilon / \cdot F(I T / T Y)$ & $V V / \cdot \wedge(1 \Delta / 1 \Delta)$ & $V N / I Q(Q / \Delta F)$ & زير ديبلم & 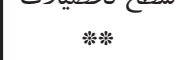 \\
\hline$s q / q \vee(\Delta / r \cdot)$ & $\Lambda \cdot / F q(I T / r r)$ & $V \cdot / T(r / Q \Delta)$ & $\wedge \varepsilon / \cdot 1(1 \cdot / r q)$ & $V D / T H(I T / M Q)$ & $V V / q \Delta(1) / q \cdot)$ & $V q / T V(1 \cdot / F V)$ & دييلم & \\
\hline $\operatorname{SN} / \mathrm{V}(\varepsilon / \Lambda))$ & $\Lambda r / r q(I Q / \cdot r)$ & $V / \Delta T(W N / Y G)$ & $\Lambda \Gamma / T F(I r / T r)$ & $V V / \Delta q(1 \Delta / \wedge q)$ & $V V / \& \Delta(I V Q / Q)$ & $V Q / \Lambda r(I Y T / F)$ & دانشخاهى & \\
\hline$\cdot / V T$ & r & $\cdot / \mathrm{VA}$ & $\cdot|\Delta|$ &.$/ 99$ &.$/ 91$ & $\cdot / M$ & $\mathrm{P}$ & \\
\hline
\end{tabular}

\section{* T test}

\section{**ANOVA}

تنها عامل تاثير كذار بر توان خودمراقبتى سالمندان نمى تواند باشد و

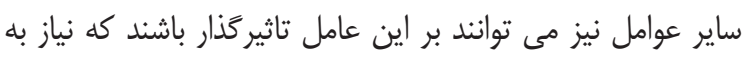
بررسى در اين زمينه مى باشد.

بررسى وضعيت سطح سواد سلامت حاكى از كسب نمرات متوسط به بالا در سالمندان تحت مطالعه بود. به طورى كه ميانخين

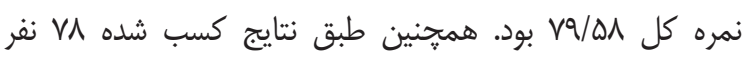

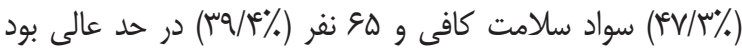

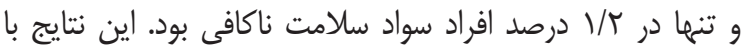

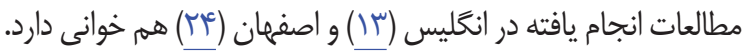
به طورى كه مطالعه انجام يافته در انغليس توسط بوستوك كه از فرم كوتاه سواد سلامت استفاده نموده اند؛ يافته ها ى آنها نشان داد

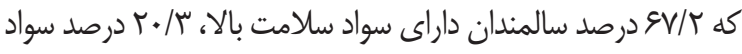

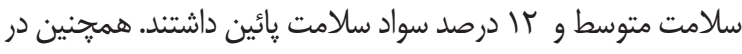

اين يزوهش به منظور بررسى ارتباط سواد سلامت و توان خود

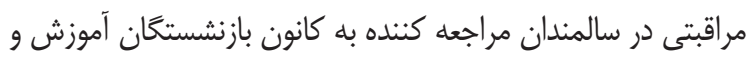

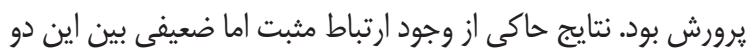
متغير بود. اين يافته در راستاى ساير مطالعات است. به عنوان مثال محسنى و همكاران در كرمان با بررسى ارتباط سطح سواد سلامت با توانايى انجام فعاليت هاى روزانه ارتباط آمارى معنى دار يافتند. از نظر آنها سواد سلامت بالا نقش مهمى در تقويت خودمراقبتى، خودمديريتى و خودكارآمدى سالمندان دارد؛ كه سبب توانائى بيشتر

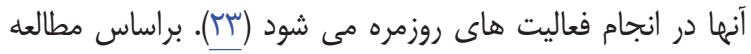
رئيسى و همكاران، سواد سلامت، عامل مهمى در اتخاذ رفتارهاى ارتقادهنده سلامت در سالمندان مى باشد (ه)). اما با وجود ارتباط

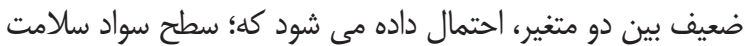


رشت با عنوان رفتارهاى خود مراقبتى و عوامل مرتبط با آن همخوانى

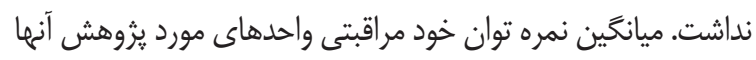

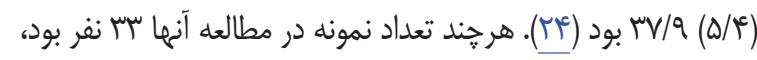

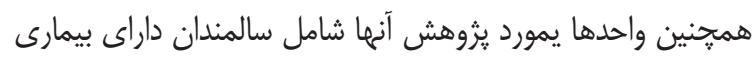

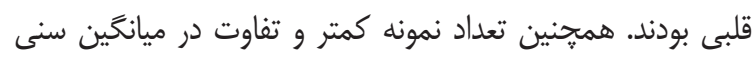
نمونه ها، در بايين بودن نتيجه تاثير داشته باشد. با توجه به بإيين

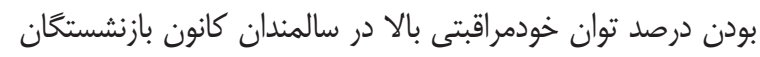

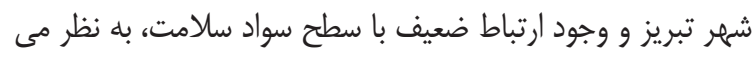
رسد ساير عوامل نيز مى توانند در توان خودمراقبتى سالمندان دخيل باشند كه توصيه مى شود عوامل موثر بر توان خود مراقبتى مورد

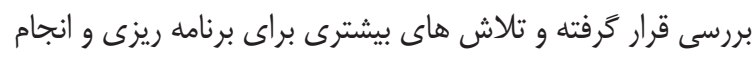

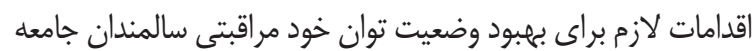

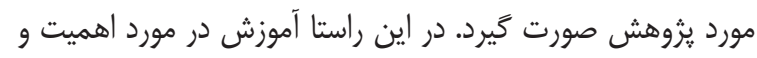
نحوه انجام رفتارهاى خودمراقبتى در ارتقاء اين رفتارها و در نتيجه

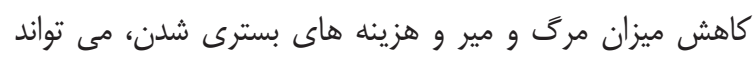

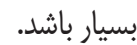

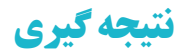

در مطالعه حاضر، با وجود ارتباط ضعيف، بين سواد سلامت و توان خودمراقبتى رابطه مثبت و معنادارى وجود داشت. همجرنين از نظر سواد سلامت افراد سالمند وضعيت متوسط به بالا داشتند اما

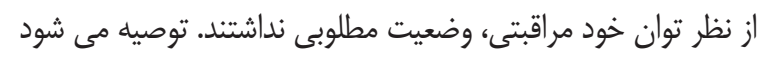

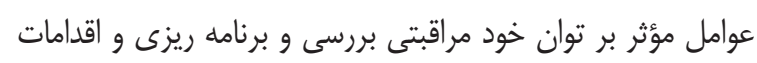

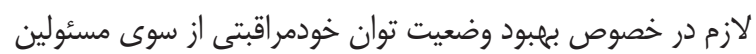

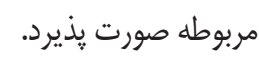

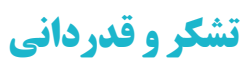

بدين وسيله از تمام مسئولين محترم كانون بازنشستكان صدا

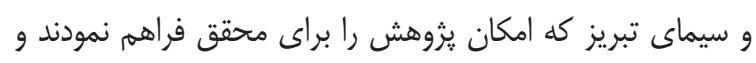

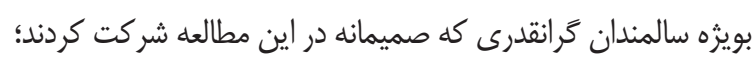

$$
\text { تقدير و تشكر مى كردد. }
$$

\section{References}

1. Sabooteh S, Shahnazi H, Mostafavi F. Health Literacy Status and Its Related Factors in the Elderlies in Dorood, Iran. 2019.

2. Hemmati Maslak Pak M, Hashemlo L. Design and psychometric properties of a self-care questionnaire for the elderly. Iranian Journal of Ageing. 2015; 10 (3): 120 -31 .
يزوهش جوادزاده و همكاران نيز كه در اصفهان و در افراد بالاى لش

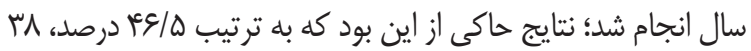

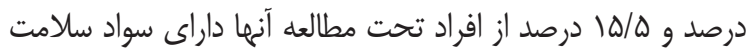

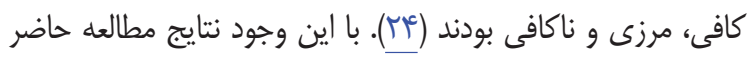

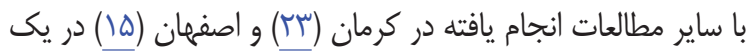
راستا نمى باشد. به طورى كه در مطالعه محسنى و همكاران در

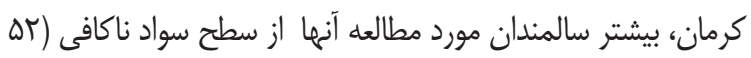

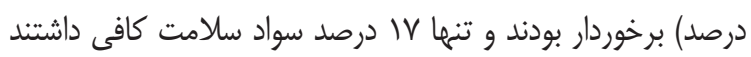
(T) (T). همنين در مطالعه رئيسى و همكاران كه در بين سالمندان

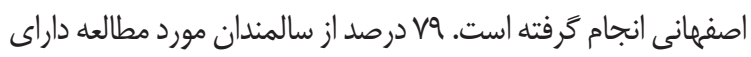

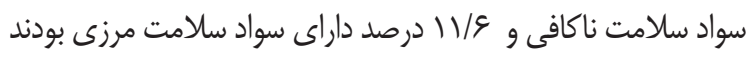

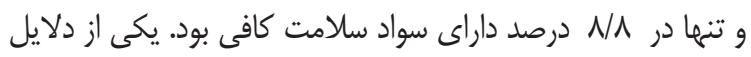
اين تفاوت مى تواند؛ ناشى از تفاوت در ويزَّى هاى افراد مورد مطالعه داله

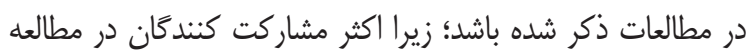
ما داراى سطح تحصيلات بالا بودند؛ در حالى كه در مطالعات مذكور

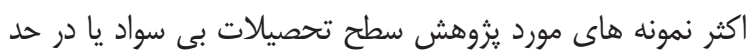
خواندن و نوشتن بود. همجنين اين مطالعات مبتنى بر جمعيت بوده

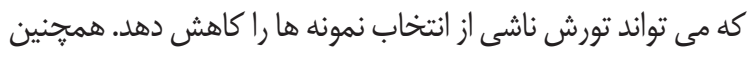
به نظر مى رسد؛ سواد سلامت ناكافى سالمندان را مى تواند ناشى از تلاز تغييرات مختلف روانى، شناختى، فيزيولوزيكى و اقتصادى همزمان با ناليا

دوره سالمندى نسبت داد (هآ). از نظر توان خودمراقبتى ميانغَين نمره كل تقريبا 99 بدست داد

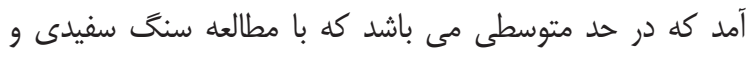

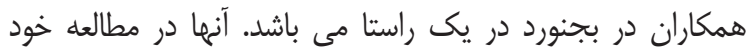

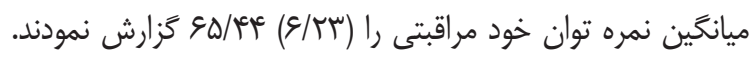

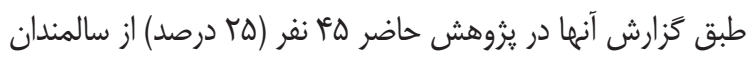

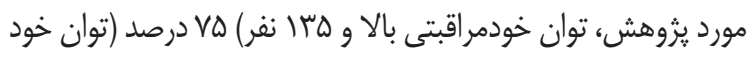

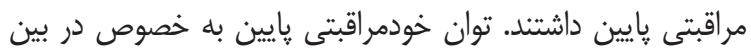

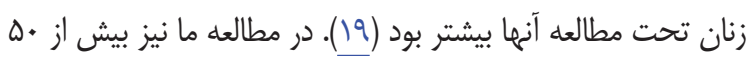

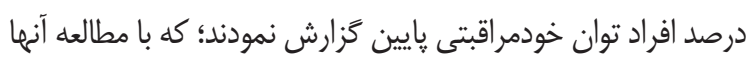

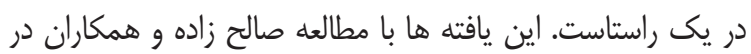

3. Mellor D, Russo S, McCabe MP, Davison TE, George K. Depression training program for caregivers of elderly care recipients: implementation and qualitative evaluation. Journal of gerontological nursing. 2008; 34 (9): 8-15.

4. Tajvar M, Arab M, Montazeri A. Determinants of health-related quality of life in elderly in Tehran, Iran. BMC public 
health. 2008; 8 (1): 323.

5. Sachdev PS, Brodaty H, Reppermund S, Kochan NA, Trollor JN, Draper B, et al. The Sydney Memory and Ageing Study (MAS): methodology and baseline medical and neuropsychiatric characteristics of an elderly epidemiological non-demented cohort of Australians aged $70-90$ years. International Psychogeriatrics. 2010; 22 (8):1248 - 64.

6. Eshaghi SR, Shahsanai A, Ardakani MM. Assessment of the Physical Activity of Elderly Population of Isfahan, Iran. Journal of Isfahan Medical School. 2011; 29 (147).

7. Fathi F, RezaeeSofi M. The relationship between health literacy and physical activity level of elderly women in the city of Urmia. Journal of Health Literacy. 2017; 2 (1): 1221.

8. Saeid M, Makarem A, Khanjani S, Bakhtyari V. Comparison of Social Health \& Quality of Life Between Residential \& Non-Residential Elderlies in Tehran. Iranian Journal of Ageing.0-.

9. James BD, Boyle PA, Bennett JS, Bennett DA. The impact of health and financial literacy on decision making in communitybased older adults. Gerontology. 2012; 58 (6): 531-9.

10. Panahi R, Ebrahimi G, Ahmadi A. Health Literacy: A Key Component of Controlling Social Determinants of Health. J Educ Community Health. 2018; 5 (1): 1-3.

11. Sørensen K, Van den Broucke S, Fullam J, Doyle G, Pelikan J, Slonska Z, et al. Health literacy and public health: a systematic review and integration of definitions and models. BMC public health. 2012; 12 (1): 80.

12. Ferguson LA, Pawlak R. Health literacy: the road to improved health outcomes. The Journal for Nurse Practitioners. 2011; 7 (2): $123-9$.

13. Bostock S, Steptoe A. Association between low functional health literacy and mortality in older adults: longitudinal cohort study. Bmj. 2012; 344: e1602.

14. De Visschere LM, Grooten L, Theuniers G, Vanobbergen JN. Oral hygiene of elderly people in long-term care institutions-a cross-sectional study. Gerodontology. 2006; 23 (4): 195 - 204.

15. Reisi M, Javadzade SH, Mostafavi F, Sharifirad G, Radjati F, Hasanzade A. Relationship between health literacy, health status, and healthy behaviors among older adults in Isfahan, Iran. Journal of education and health promotion. 2012; 1 (1): 31.

16. BIDI F, HASSANPOUR K, Ranjbarzadeh A, ARAB KA. Effectiveness of educational program on knowledge, attitude, self care and life style in patients with type II diabetes. 2013.

17. Didarloo A, Shojaeizadeh D, Asl RG, Habibzadeh H, Niknami S, Pourali R. Prediction of self-management behavior among Iranian women with type 2 diabetes: application of the theory of reasoned action along with self-efficacy (etra). Iranian Red Crescent Medical Journal. 2012; 14 (2): 86.

18. Habibi A, Nemadi-Vosoughi M, Habibi S, Mohammadi M. Quality of life and prevalence of chronic illnesses among elderly people: A cross-sectional survey. Journal of Health. 2012; 3 (1): 58 - 66.

19. SangSefidi S, Ghanbari Moghaddam A, Mohamadzadeh M, Karbalaee Z, Mohammadi M. Self-care and its predictive role in the quality of life of the elderly living in the community. Journal of Gerontology. 2018; 2 (4): 64 - 70.

20. Landefeld CS, Palmer RM, Kresevic DM, Fortinsky RH, Kowal J. A randomized trial of care in a hospital medical unit especially designed to improve the functional outcomes of acutely ill older patients. New England Journal of Medicine. 1995; 332 (20): 133844.

21. Panahi R, Osmani F, Sahraei M, Ebrahimi S, Shamsizadeh Nehadghashti M, Javanmardi E. Relationship of Health Literacy and Quality of Life in Adults Residing in Karaj, Iran. J Educ Community Health. 2018; 4 (4): $13-9$.

22. Montazeri A, Tavousi M, Rakhshani F, Azin SA, Jahangiri K, Ebadi M, et al. Health Literacy for Iranian Adults (HELIA): development and psychometric properties. 2014. 
23. Mohseni M, Khanjani N, Iranpour A, Tabe R, Borhaninejad VR. The relationship between health literacy and health status among elderly people in Kerman. Iranian Journal of Ageing. 2015; 10 (2): 146 - 55.

24. Javadzade SH, Sharifirad G, Radjati F, Mostafavi F, Reisi M, Hasanzade A. Relationship between health literacy, health status, and healthy behaviors among older adults in Isfahan, Iran. Journal of Education and Health Promotion. 2011; 1:31.

25. Salehzadeh A, Rahmatpour P. Self-care behaviors and related factors in patients with heart failure reffering to medical \& educational center of heart in Rasht.. Journal of Holistic Nursing And Midwifery. 2013; 23 (1): 22 - 9. 